\title{
Phosphorylation of the amyloid $\beta$-peptide at Ser26 stabilizes oligomeric assembly and increases neurotoxicity
}

\author{
Sathish Kumar ${ }^{1}$ Oliver Wirths ${ }^{2} \cdot$ Kathrin Stüber $^{3,4} \cdot$ Patrick Wunderlich $^{1}$. \\ Philipp Koch $^{3,4} \cdot$ Sandra Theil ${ }^{1} \cdot$ Nasrollah Rezaei-Ghaleh ${ }^{5}$. \\ Markus Zweckstetter ${ }^{5,6,7}$ - Thomas A. Bayer ${ }^{2}$ - Oliver Brüstle Th, $^{3,4}$ Dietmar R. Thal ${ }^{9}$. \\ Jochen Walter ${ }^{1}$
}

Received: 10 November 2015 / Revised: 10 February 2016 / Accepted: 10 February 2016 / Published online: 22 February 2016

(c) The Author(s) 2016. This article is published with open access at Springerlink.com

\begin{abstract}
Aggregation and toxicity of the amyloid $\beta$-peptide $(\mathrm{A} \beta)$ are considered as critical events in the initiation and progression of Alzheimer's disease (AD). Recent evidence indicated that soluble oligomeric $A \beta$ assemblies exert pronounced toxicity, rather than larger fibrillar aggregates that deposit in the forms of extracellular plaques. While some rare mutations in the $A \beta$ sequence that cause early-onset $\mathrm{AD}$ promote the oligomerization, molecular mechanisms that induce the formation or stabilization of oligomers of the wild-type $A \beta$ remain unclear. Here, we identified an $A \beta$ variant phosphorylated at Ser26 residue (pSer26A $\beta$ ) in transgenic mouse models of $A D$ and in human brain that shows contrasting spatio-temporal distribution as compared to non-phosphorylated $A \beta$ (npA $\beta$ ) or other modified $A \beta$ species. pSer26A $\beta$ is particularly abundant in intraneuronal deposits at very early stages of $\mathrm{AD}$, but much less in extracellular plaques. pSer26A $\beta$ assembles into a specific oligomeric form that does not proceed
\end{abstract}

Electronic supplementary material The online version of this article (doi:10.1007/s00401-016-1546-0) contains supplementary material, which is available to authorized users.

Jochen Walter

Jochen.Walter@ukb.uni-bonn.de

1 Department of Neurology, University of Bonn, 53127 Bonn, Germany

2 Division of Molecular Psychiatry, Department of Psychiatry and Psychotherapy, University Medical Center (UMG), Georg-August-University Göttingen, Von-Siebold-Str. 5, 37075 Göttingen, Germany

3 Institute of Reconstructive Neurobiology, University of Bonn, 53127 Bonn, Germany

4 LIFE \& BRAIN Center, University of Bonn, 53127 Bonn, Germany further into larger fibrillar aggregates, and accumulates in characteristic intracellular compartments of granulovacuolar degeneration together with TDP-43 and phosphorylated tau. Importantly, pSer $26 \mathrm{~A} \beta$ oligomers exert increased toxicity in human neurons as compared to other known $\mathrm{A} \beta$ species. Thus, pSer $26 \mathrm{~A} \beta$ could represent a critical species in the neurodegeneration during $\mathrm{AD}$ pathogenesis.

Keywords Alzheimer's disease · Phosphorylation · Protein aggregation $\cdot$ Intraneuronal Abeta $\cdot$ Amyloid oligomer $\cdot$ Granulovacuolar degeneration

\section{Introduction}

Alzheimer's disease (AD) is the most common form of dementia and characterized by the combined occurrence of extracellular amyloid plaques and intraneuronal neurofibrillary tangles [44]. The accumulation of amyloid- $\beta(\mathrm{A} \beta)$ as oligomers and fibrils is an early event in the development of $\mathrm{AD}$. $\mathrm{A} \beta$ peptides derive from the

5 German Center for Neurodegenerative Diseases (DZNE), 37077 Göttingen, Germany

6 Department for NMR-Based Structural Biology, Max Planck Institute for Biophysical Chemistry, 37077 Göttingen, Germany

7 Center for the Molecular Physiology of the Brain, University Medical Center, 37077 Göttingen, Germany

8 German Center for Neurodegenerative Diseases (DZNE), 53175 Bonn, Germany

9 Laboratory of Neuropathology-Institute of Pathology, University of Ulm, 89081 Ulm, Germany 
proteolytic processing of the amyloid precursor protein (APP) by $\beta$ - and $\gamma$-secretases [54]. A critical role of $A \beta$ in the pathogenesis of $\mathrm{AD}$ is strongly supported by mutations in the genes encoding APP or presenilin 1 and 2 that cause early-onset familial forms of AD (FAD) [45]. These mutations commonly increase the production and/ or aggregation of $A \beta$ and deposition of amyloid plaques $[7,9,18]$. However, the vast majority of cases occur late in life without mutations in the amyloid precursor protein (APP) or presenilins (PS) that cause familial forms of early-onset $\mathrm{AD}$.

The $\mathrm{A} \beta$ peptide is natively unfolded and tends to aggregate into soluble oligomers, protofibrils and fibrils [3]. Recent studies suggest that the toxicity of $A \beta$ and other amyloidogenic proteins is not only exerted by insoluble fibrils, but rather by soluble oligomeric intermediates [11, 19, 33, 52]. Strong evidence indicates a critical role of soluble $\mathrm{A} \beta$ oligomers in the pathogenesis of $\mathrm{AD}[4$, 19,32]. While extracellular deposits of this peptide in form of plaques only weakly correlate with neuronal cell death and clinical stage of $\mathrm{AD}$, soluble oligomers $[11,32,52]$ and intracellular $[17,56]$ deposits of $A \beta$ have been shown to associate more closely with disease progression. Certain FAD mutations in the $A \beta$ domain facilitate the formation of such assemblies [13, 23, 25, 34, 49]. However, these mutations are rare and mechanisms that drive the aggregation of wild-type $A \beta$ during the pathogenesis of much more common sporadic forms of AD are largely unclear.

We recently demonstrated that extracellular $\mathrm{A} \beta$ undergoes phosphorylation by secreted variants of protein kinase A [26]. Phosphorylation of $A \beta$ at serine (Ser) 8 residue promotes its aggregation into oligomeric and fibrillar assemblies [26]. Phosphorylation of Ser8 also attenuated the proteolytic degradation of $A \beta$ by certain proteases and clearance by microglial cells [27]. By employing pSer8A $\beta$ specific monoclonal antibodies, we showed the early intraneuronal accumulation and increased aggregation of pSer8A $\beta$ in transgenic mouse and human brains [29, 42]. These findings highlight the plausible role of $A \beta$ phosphorylation in $\mathrm{AD}$ pathogenesis.

A $\beta$ can also undergo phosphorylation at Ser26 which modulates its aggregation in vitro [36, 41]. Here we investigated the effect of Ser26 phosphorylation on aggregation, toxicity and its presence in human AD brains and transgenic mouse models. We demonstrate a peculiar deposition of Ser26 phosphorylated $A \beta$ in human and transgenic mouse brain that differs from that observed for other $A \beta$ species. Notably, phosphorylation of $A \beta$ at Ser26 strongly promotes the formation and stabilization of low molecular weight soluble $A \beta$ oligomers with increased toxicity on human neurons.

\section{Materials and methods}

\section{Reagents and antibodies}

Synthetic non-phosphorylated $A \beta 1-40$ (npA $\beta$ ), phosphorylated $A \beta 1-40$ variants (pSer8A $\beta$ and $p S e r 26 A \beta$ ) and other modified $\mathrm{A} \beta$ (Tyr10 nitrated, Glu3 pyroglutamate and truncated 3-42) peptides were purchased from Peptide Speciality Laboratory (PSL, Germany). Thioflavin T, 4',6-diamidino-2'phenylindole dihydrochloride (DAPI), 3,3'-diamino-benzidine (DAB) and methanol were from Sigma-Aldrich (USA). Congo red was purchased from AppliChem GmbH (Germany). Precast 4-12 \% NuPAGE Bis-Tris mini and midi gels, prestained protein molecular weight markers and PrestoBlue ${ }^{\circledR}$ cell viability reagent were from Life technologies (Germany). Nitrocellulose membranes were from Schleicher and Schuell (Germany). ECL Western blotting detection reagents were from GE Healthcare (UK). Vectastain ABC kit and hematoxylin were from Vector laboratories (USA). Protease and phosphatase inhibitors were from Roche laboratories (Germany). BCA ${ }^{\mathrm{TM}}$ protein assay kit was from Thermo Scientific (USA). Monoclonal $\mathrm{A} \beta$ antibodies $6 \mathrm{E} 10$ and $4 \mathrm{G} 8$ were purchased from Covance Laboratories (USA), and 82E1 antibody was from IBL Corporation (Japan). Mouse monoclonal GFAP antibody was from Synaptic systems (Germany), and 22C11 antibody specific against amyloid precursor protein (APP) (a.a. 66-81 of APP at N-terminus) was from Merck Millipore (Germany). A Mouse monoclonal Phospho-PHF-tau specific AT8 antibody was purchased from Thermo scientific (USA). Rabbit polyclonal anti-CK1 $\delta$ (antiserum 108) and anti-CK1ع (antiserum 712) were generously provided by Dr. Uwe Knippschild from University Hospital Ulm, Germany. The anti-mouse, anti-rabbit secondary antibodies conjugated to horseradish peroxidase were from Sigma Aldrich (Germany), Secondary fluorescent anti-mouse 594 DyLight, anti-rabbit 488 antibodies were from Thermo Scientific (USA), IRDye800CW and IRDye680RD were from LI-COR Biotechnology. Biotinylated secondary anti-mouse and anti-rabbit antibodies were from DAKO (Glostrup, Denmark). The dilutions of each antibody stock are mentioned for the respective methods or in figure legends.

\section{Generation of pSer26A $\beta$-specific antibodies}

The pSer26A $\beta$-specific polyclonal antibody SA6192 was generated in rabbits by injecting synthetic $A \beta 19-31$ peptides with Ser26 in phosphorylated state (antigen sequence: FFAEDVG (p) SNKGAI) conjugated with keyhole limpet hemocyanin (KLH) (Eurogentec, Belgium). Phosphorylation state-specific antibodies were purified from the serum 
by double-affinity purification using $\mathrm{pSer} 26 \mathrm{~A} \beta$ and $\mathrm{npA} \beta$ peptide. The specificity of the purified antibodies was characterized by enzyme-linked immunosorbent assay (ELISA) and Western blotting (WB). Further details are described in the Supplementary Information.

\section{Biochemical and immunohistochemical detection of pSer26A $\beta$ in transgenic mouse brains}

For biochemical analysis of pSer26A $\beta$, whole brain homogenates from APP/PS1KI were prepared as described previously [26, 29]. Immunohistochemistry was performed on $4 \mu \mathrm{m}$ sagittal paraffin sections as described previously [58]. Further details of $A \beta$ extraction and immunohistochemistry of transgenic mouse brains are described in the Supplementary Information.

\section{Immunohistochemistry of human AD brain}

Human autopsy brains were received from University Hospital Bonn (Germany) and from University Hospital Ulm (Germany) in accordance with the laws and the permission of the local ethical committees. Post-mortem diagnosis of Alzheimer's disease was carried out according to the NIAReagan Criteria [6, 37]. All procedures were conducted in accordance with the laws and the permission of the local ethical committees. Further detailed methods and information on cases are given in the Supplementary Information.

\section{A $\beta$ aggregation assays}

$\mathrm{A} \beta$ aggregation kinetics by Thioflavin $\mathrm{T}$ (ThT) and Congo Red (CR) binding assays were performed as described previously [26]. Morphology of the aggregates was characterized by transmission electron and atomic force microscopy. Further details are given in the Supplementary Information.

\section{Cell viability assays}

Cell viability assays were carried out with human neuroblastoma cells (SK-N-SH), embryonic stem cell (ES)-derived neurons and induced pluripotent stem cell (iPSC)-derived neurons. Further details on cultivation and assay procedures are described in the Supplementary Information.

\section{Results}

\section{Phosphorylation state-specific antibodies detect pSer26A $\beta$ aggregates in transgenic mouse models of AD}

Post-translational modifications could alter the aggregation, degradation and toxicity of $\mathrm{A} \beta[26-28,30,43,57]$.
Synthetic A $\beta$ peptides phosphorylated on either Ser8 or Ser26 showed faster formation of oligomeric assemblies in vitro $[26,41]$. To specifically investigate Ser26-phosphorylated $A \beta$ (pSer26A $\beta$ ) species in vivo, we generated phosphorylation state-specific antibodies (Fig. 1a). Double-affinity purified antibody SA6192 was highly specific for $A \beta$ phosphorylated at Ser26 (Fig. 1b). It did not detect Ser8 phosphorylated (pSer8A $\beta$ ), pyroGlu-modified (pyroA $\beta 3-42)$, N-terminally truncated $(\mathrm{A} \beta 3-42)$, or nitrosylated (3NTyr10-A $\beta$ ) $A \beta$ variants (Fig. 1c), while the generic 4G8 antibody which recognizes an epitope between amino acids 17 and 24 of the $A \beta$ domain, detected $n p A \beta$ (Fig. 1b) and all the tested peptide variants similarly (Fig. 1c). SA6192 did not detect full-length APP or its C-terminal fragments in brain extracts of transgenic mice, suggesting selective phosphorylation of Ser26 after the generation of $A \beta$ (Supplementary Fig. 1a, b). Detection of pSer26A $\beta$ by the SA6192 antibody was efficiently blocked with synthetic pSer26A $\beta$, but not with synthetic $\mathrm{npA} \beta$ peptide, further demonstrating the specificity of this antibody (Supplementary Fig. 1c, d). We took advantage of the SA6192 antibody to characterize the deposition of pSer26A $\beta$ peptides in transgenic mouse brains. Western immunoblot analysis of brain extracts from APP/PS1KI transgenic mice showed the presence of pSer26A $\beta$ peptides in water-soluble (predominantly containing extracellular soluble $A \beta$ ) and in SDS-soluble fractions (predominantly containing intracellular and membrane-associated $\mathrm{A} \beta$ ) at 6 months of age (Fig. 1d, e). pSer26A $\beta$ reactivity was not detected in non-transgenic mouse brains. The quantification of the SA6192 immunoreactivity of watersoluble APP/PS1KI transgenic mouse brain extracts using synthetic pSer26A $\beta$ as standard revealed that $\sim 10-15 \%$ of extracted monomeric $\mathrm{A} \beta$ is in a phosphorylated state (50 $\mu \mathrm{g}$ protein from water-soluble brain extracts contained $\sim 0.17 \pm 0.03 \mathrm{ng}$ of $\mathrm{pSer} 26 \mathrm{~A} \beta$ and $\sim 1.55 \pm 0.09 \mathrm{ng}$ of total $\mathrm{A} \beta$ ).

In 2-month-old transgenic mice, pSer26A $\beta$ was not detectable by Western immunoblotting (Fig. 1d, e). Interestingly, immunohistochemistry revealed abundant deposition of pSer26A $\beta$ intraneuronally in 2-month-old animals when extracellular plaques were hardly detectable (Fig. 1f). The pronounced intraneuronal reactivity was also detected in older mice in different brain regions. Occasionally, extracellular deposits were also positive for $\mathrm{pSer} 26 \mathrm{~A} \beta$ (Fig. 1f). Double-labelling with pSer26A $\beta$ and generic $\mathrm{A} \beta$ antibodies specifically demonstrate preferential intraneuronal accumulation of pSer26A $\beta$ in the presence of pronounced extracellular plaques (Fig. 1g). As compared to staining with generic $A \beta$ antibodies, $\mathrm{pSer} 26 \mathrm{~A} \beta$ reactivity was restricted to structures in the core of the plaques in aged transgenic mouse brains (10 months) (Supplementary Fig. 2a). Double-staining 
a

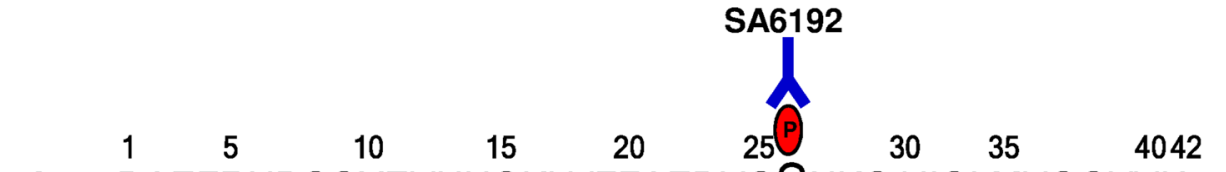

A $\beta$ DAEFRHDSGYEVHHQKLVFFAEDVGSNKGAIIGLMVGGVVIA

b
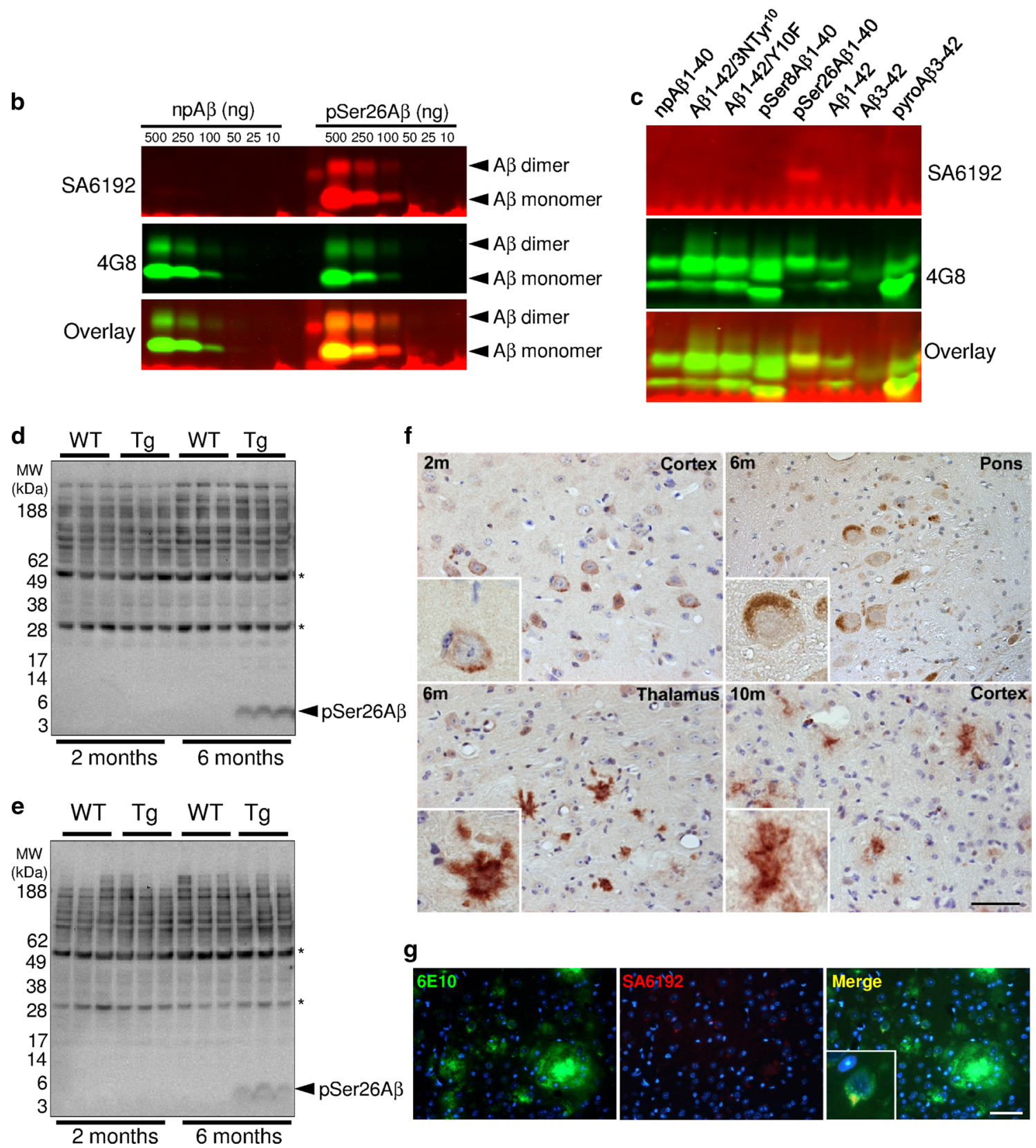

also revealed the association of reactive astrocytes in the vicinity of neurons with intracellular pSer26A $\beta$ (Supplementary Fig. 2b). Reactivity of the SA6192 antibody was not observed in control mice (Supplementary Fig. 3c).
SA6192 immunoreactivity in transgenic mice was efficiently blocked by synthetic pSer26A $\beta$, further supporting the specific detection of pSer26A $\beta$ deposits (Supplementary Fig. 3b, c). Additional immunohistochemical staining 
4Fig. 1 Specific detection of A $\beta$ phosphorylated at Ser26 in transgenic mouse models of $\mathrm{AD}$. a Amino acid sequence of human $\mathrm{A} \beta$ indicating the phosphorylation site at Ser26. Underlined glutamic acid $(E)$ and aspartic acid $(D)$ residues comprise a consensus phosphorylation sequence for casein kinase 1. b, c SA6192 antibody specifically detects pSer26A $\beta$ in immunoblotting without cross-reactivity against other post-translationally modified or non-modified $A \beta$ variants (c). Generic 4G8 antibody recognizes non-modified and all the modified $\mathrm{A} \beta$ variants $(\mathbf{b}, \mathbf{c})$. d, e WB analysis of sucrose (d) and SDS (e) fractions of 2- and 6-months-old APP/PS1KI (Tg) and non-Tg (WT) mouse brain homogenates revealed the presence of $\mathrm{pSer} 26 \mathrm{~A} \beta$ in vivo. SA6192 showed no reactivity with endogenous mouse APP in nontransgenic mice, further demonstrating the specificity of this antibody (Supplementary Fig. 1a, b). The bands indicated by asterisks likely represent heavy and light chains of endogenous immunoglobulins. f Immunohistochemical staining of 2-, 6-, and 10-month-old APP/ PS1KI mouse brain tissues with SA6192 antibody demonstrates the occurrence of intraneuronal (2 and 6 months) and extracellular (10 months) pSer26A $\beta$ deposits in different brain regions. $g$ Doublelabelling with 6E10 (green) and SA6192 (red) revealed intraneuronal immunoreactivity of SA6192. The inset in the merged image shows a higher magnification of 6E10 and SA6192 co-localization (yellow) within the cell body of a cortical neuron. Scale bars $\mathbf{f}$ and $\mathbf{g} 50 \mu \mathrm{m}$

of 6- and 12-month-old 5XFAD mouse brains also demonstrated intraneuronal accumulation of $\mathrm{pSer} 26 \mathrm{~A} \beta$ aggregates and few extracellular pSer $26 \mathrm{~A} \beta$ positive plaques (Supplementary Fig. 4). These data demonstrate a unique pattern of deposition of pSer26A $\beta$ that differs from that of other $A \beta$ species, including post-translationally modified variants like $\mathrm{pSer} 8 \mathrm{~A} \beta[26,29]$ or pyroglutaminated $\mathrm{A} \beta[43,57]$.

\section{Selective intraneuronal deposition of $\operatorname{pSer} 26 \mathrm{~A} \beta$ in human brains}

Human AD brains also revealed a specific accumulation pattern of pSer $26 \mathrm{~A} \beta$. pSer $26 \mathrm{~A} \beta$ could be detected in individual cored-neuritic plaques and partially overlapped with the pattern of antibodies raised against the middle region of $A \beta$ (4G8; epitope 17-24) (Fig. 2a, b; Supplementary Fig. 5a, b). pSer26A $\beta$ was also detected in APP-positive dystrophic neurites in these plaques (Fig. 2c, d). AntipSer26A $\beta$ also stained additional material indicating the deposition of pSer26A $\beta$ within extracellular plaques (Supplementary Fig. 5a, c). A considerable number of diffuse plaques were also stained with anti-pSer26A $\beta$ (Supplementary Fig. 5d). By analysis of the distinct plaque-types occurring in the medial temporal lobe, pSer26A $\beta$-positive material was restricted to diffuse, cored and neuritic plaques as well as subpial band-like amyloid (Supplementary Fig. 5d), whereas fleecy amyloid and presubicular lake-like amyloid was not stained in the cases studied here (Supplementary Table 1). Moreover, staining of pSer26A $\beta$ in amyloid plaques was restricted to the symptomatic AD cases observed here. No pSer26A $\beta$-positive plaques are observed in pathologically diagnosed preclinical $\mathrm{AD}$ (p-preAD) cases.

Notably, pSer26A $\beta$ was also detected inside of neurons that showed no or only faint reactivity with antibodies against APP or generic A $\beta$ (Fig. 2a-d, arrowhead). The diffuse neuronal staining was not only detected in $\mathrm{AD}$, but also in pathological pre-AD and even in control cases. The intraneuronal pSer26A $\beta$ showed the typical morphological pattern of granulovacuolar degeneration (GVD) [48]. The morphological distribution of the pSer26A $\beta$-positive granules predominantly in neurons of the CA1-subiculum regions of the hippocampal formation fitted with that known for GVD (Fig. 2e-g) [48]. Interestingly, most neurons with GVD lesions also contained abnormally phosphorylated $\tau$-protein (Fig. $2 \mathrm{~h}-\mathrm{j}$ ), phosphorylated transactive response DNA-binding protein (pTDP43) and casein kinase $1 \delta / \varepsilon$ (Supplementary Fig. 5e-h). Notably, CK1 indeed could phosphorylate $\mathrm{A} \beta$ at Ser26 (Supplementary Fig. 6a-d), suggesting a phosphorylation of $A \beta$ by CK1 in GVD compartments. Interestingly, pSer26A $\beta$ was consistently detected together with pTDP43 in GVD, even in p-preAD and non-AD control cases (Supplementary Table 2).

\section{Peculiar aggregation behaviour of pSer26A $\beta$}

Phosphorylation of $A \beta$ at Ser26 alters plasticity of a critical turn region and impairs fibrillization [41]. Accordingly, pSer26A $\beta$ showed strongly reduced binding of Congo Red (CR) and Thioflavin T (ThT) as compared to npA $\beta$ (Fig. 3a; Supplementary Fig. 7a). In contrast, phosphorylation at Ser8 strongly increased CR and ThT binding. Kinetic analysis revealed a slight but very rapid increase in ThT binding of pSer26A $\beta$ that did not further increase over time (Supplementary Fig. 7a; inset), indicating rapid formation of smaller assemblies without proceeding to fibril formation (Fig. 3b; Supplementary Fig. 7b). In denaturing (Fig. 3c) and non-denaturing PAGE (Fig. 3d), pSer26A $\beta$ was detected as smaller oligomeric assemblies (i.e., dimers and trimers) already at very short incubation periods that 

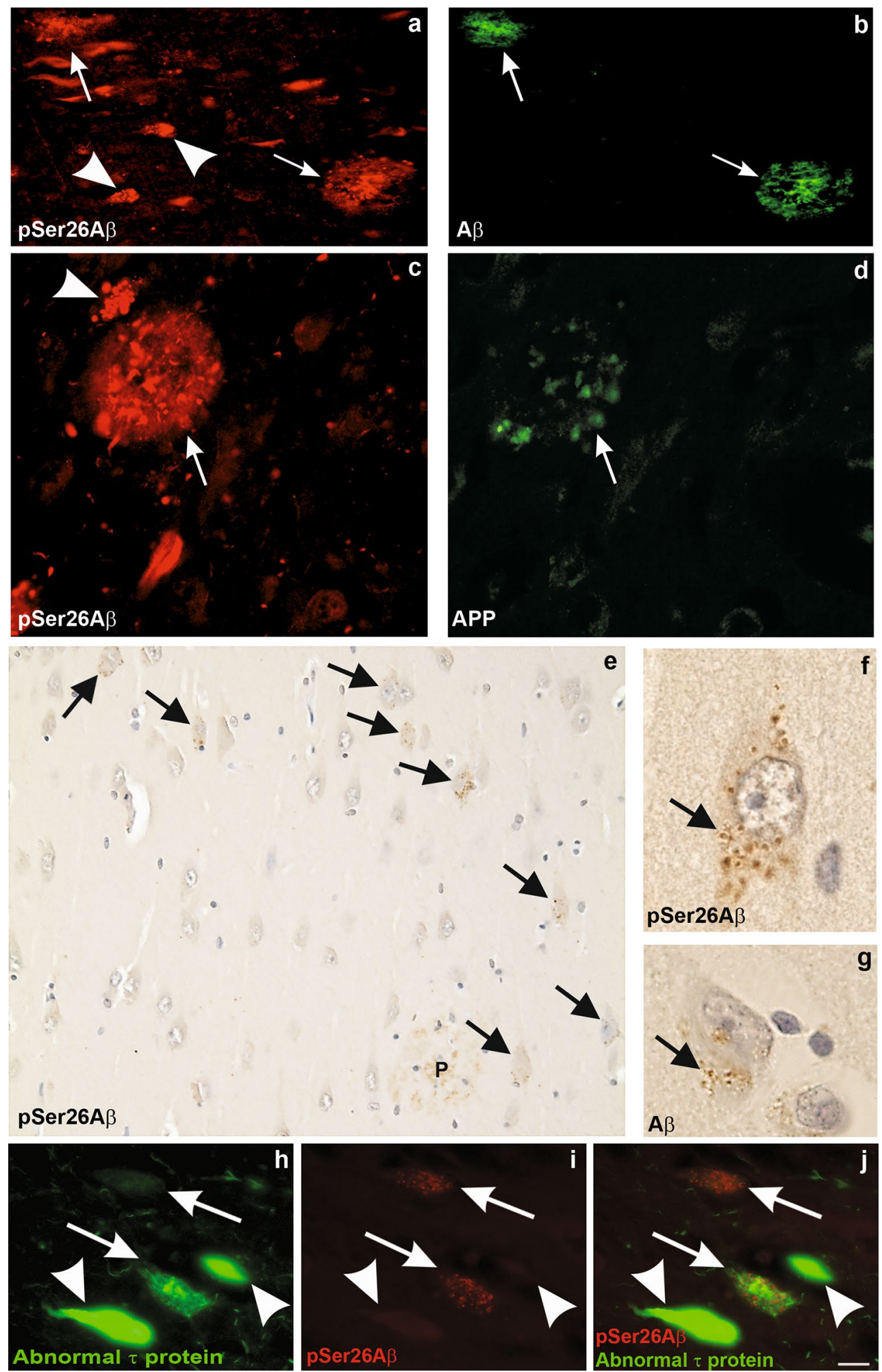

persist even after longer incubation time, consistent with a very rapid self-assembly of this $A \beta$ variant. As already indicated by the CR and ThT binding assays, pSer8A $\beta$ reached a higher aggregation state than $n p A \beta$ represented by the increased reactivity in the upper parts of the gel (Fig. 3bd; Supplementary Fig. 7b). Even after longer incubation 
\Fig. 2 Detection of intraneuronal pSer26A $\beta$ aggregates and GVDs in human $\mathrm{AD}$ brains. Detection of $\mathrm{pSer} 26 \mathrm{~A} \beta$ in extracellular (arrows) and intraneuronal (arrowheads) deposits in the hippocampal CA1 subfield $(\mathbf{a}, \mathbf{c}, \mathbf{e}, \mathbf{f}, \mathbf{g}, \mathbf{i})$. The extracellular $\mathrm{A} \beta$ plaques are co-stained with anti-A $\beta_{17-24}$ (4G8) (b), and anti-APP antibody (22C11) (d). The central amyloid core is stained with SA6192 and 4G8 but not with anti-APP indicating the co-deposition of $\mathrm{pSer} 26 \mathrm{~A} \beta$ together with non-phosphorylated $A \beta$ in plaques (Supplementary Fig. 5a-c). Note the intraneuronal globular aggregates reactivity is selectively observed with pSer26A $\beta$ (arrowhead in a, c), but not with APP antibodies. Immunohistochemical analysis demonstrates strong intraneuronal granular cytoplasmic pSer26A $\beta$ inclusions (arrows in e), and only weakly stained extracellular pSer26A $\beta$-positive plaques $(P$ in e) (Supplementary Fig. 4d). These granular inclusions exhibit the morphological pattern of granulovacuolar degeneration (GVD) and most frequently occur in the CA1-subiculum area of the hippocampal formation (arrow in f). GVD was also detected by anti-A $\beta_{17-24}$ staining (arrow in g). pSer26A $\beta$-positive GVD lesions colocalized with abnormal-phosphorylated $\tau$ in neurons (arrows in $\mathbf{h}-\mathbf{j}$ ). Note that neurofibrillary tangles were not labelled with anti-pSer26A $\beta$ antibody (arrowhead in $\mathbf{h}-\mathbf{j}$ ). The panels in this figure are representative images from 4 different AD brains (a, b case \# 7; c, $\mathbf{d}$ case \# 3, e-g case \# 1 and $\mathbf{h}, \mathbf{i}$ case \# 5 of supplementary Table 2). Scale bars $\mathbf{a}$ and b $50 \mu \mathrm{m}$; c and d $30 \mu \mathrm{m} ; \mathbf{e} 20 \mu \mathrm{m} ; \mathbf{f}$ and $\mathbf{g} 5 \mu \mathrm{m} ; \mathbf{h}-\mathbf{j} 20 \mu \mathrm{m}$

periods, pSer26A $\beta$ only formed intermediate oligomeric forms migrating between 30 and $80 \mathrm{kDa}$ in SDS-containing denaturing gels (Fig. 3c) and between 30 and $400 \mathrm{kDa}$ in native gels (Fig. $3 \mathrm{~d}$ ). npA $\beta$ and pSer8A $\beta$ formed higher oligomeric and fibrillar $(<1000 \mathrm{kDa})$ assemblies (Fig. 3c, d). Transmission electron microscopy (TEM) and atomic force microscopy (AFM) revealed only heterogeneous globular species of various sizes of $\mathrm{pSer} 26 \mathrm{~A} \beta$ without formation of fibrillar structures, as seen with npA $\beta$ peptide (Fig. 3e, f; Supplementary Fig. 8).

\section{Increased toxicity of pSer26A $\beta$ in human neurons}

To assess the toxicity of the pSer26A $\beta$ in a human neuronal model, we used human neuroblastoma cells, human neurons differentiated from embryonic stem cell (ESC) and induced pluripotent stem cell (iPSC)-derived neural stem cells (lt-NES) cells. In a first set of experiments, the different $\mathrm{A} \beta$ variants were added without prior aggregation to human neuroblastoma cells (Fig. 4a) and to differentiated neurons (Fig. 4b). As compared to the nonphosphorylated peptide, $A \beta$ pseudophosphorylated at position $26(\mathrm{~A} \beta S 26 \mathrm{D})$ induced increased toxicity in neuroblastoma cells (Fig. 4a) and also in hESC-derived neurons (Fig. 4b). Even at concentrations when npA $\beta$ showed no overt toxicity, A $\beta S 26 \mathrm{D}$ impaired neuronal metabolism comparable to the effect of a tenfold higher concentration of npA $\beta$ in both neuroblastoma cells (Fig. 4a) and human ESC-derived neurons (Fig. 4b). To specifically assess the toxic properties of different $A \beta$ variants depending on their aggregation state, we next exposed human iPSC-derived neurons to preformed assemblies of $n p A \beta, p S e r 8 A \beta$ and $p S e r 26 A \beta$. Dot blot analysis of the different preformed $A \beta$ assemblies showed significant differences in their immunoreactivity against conformationdependent anti-oligomer antibodies such as A11 (Fig. 4c) and OC (Fig. 4d; Supplementary Fig. 9) [21, 22]. npA $\beta$ and $\mathrm{pSer} 8 \mathrm{~A} \beta$ assemblies were detected by both $\mathrm{A} 11$ and OC antibodies after 2-6 h of incubation. However, both antibodies revealed only very little if any reactivity for assemblies formed by pSer26A $\beta$ (Fig. 4c, d). NativePAGE analysis showed that the samples from different incubation times contained assemblies of different sizes (Fig. 4e). After 2-6 h of aggregation, samples of $n p A \beta$ and $\mathrm{pSer} 8 \mathrm{~A} \beta$ contained oligomers of intermediate size $(150-480 \mathrm{kDa})$. After $6-24 \mathrm{~h}, \mathrm{npA} \beta$ and $\mathrm{pSer} 8 \mathrm{~A} \beta$ also formed high molecular weight assemblies, which were not detected with pSer26A $\beta$. Instead, oligomers of intermediate size formed by pSer26A $\beta$ were prominently detected at $24 \mathrm{~h}$ of incubation. Monomeric and dimeric $\mathrm{A} \beta$ were detected at all time points. However, these forms might also result from dissociation of aggregates, even during native-PAGE conditions. Notably, npA $\beta$ and $\mathrm{pSer} 8 \mathrm{~A} \beta$ variants exerted toxicity only at 6 and $2 \mathrm{~h}$ of pre-aggregation, respectively, and lost their toxic activity during extended aggregation (Fig. 4e, f). After longer aggregation periods, toxicity of $\mathrm{npA} \beta$ and $\mathrm{pSer} 8 \mathrm{~A} \beta$ was decreased. A similar behaviour was previously observed for pyroE3-modified $\mathrm{A} \beta$ [39]. Compared to $\mathrm{npA} \beta$ and $\mathrm{pSer} 8 \mathrm{~A} \beta$, pSer $26 \mathrm{~A} \beta$ exerted strongest toxicity (Fig. 4f). Toxicity of pSer26A $\beta$ was observed after $24 \mathrm{~h}$ of pre-aggregation. Interestingly, during this time of incubation, pSer26A $\beta$ also formed intermediate-size oligomers of $150-480 \mathrm{kDa}$, but no larger assemblies or fibrils (Fig. 4e, f).

\section{Discussion}

The present data reveal peculiar characteristics of Ser26 phosphorylated $A \beta$ in aggregation, brain deposition and neurotoxicity. In contrast to non-modified $A \beta$ or other $A \beta$ variants with post-translational modifications in the $\mathrm{N}$-terminal domain of $A \beta$, including Glu3 pyroglutaminated [43, 57], Ser8 phosphorylated [26, 29], Tyr10 nitrated forms of $\mathrm{A} \beta$ [30], pSer26A $\beta$ does not form higher prefibrillar or fibrillar assemblies. Instead, pSer $26 \mathrm{~A} \beta$ forms stable oligomers of intermediate size that exert pronounced toxicity on human neurons.

In many neurodegenerative diseases, soluble oligomers of pathogenic proteins are considered as the principal toxic forms, and the accumulation of large fibrillar deposits 

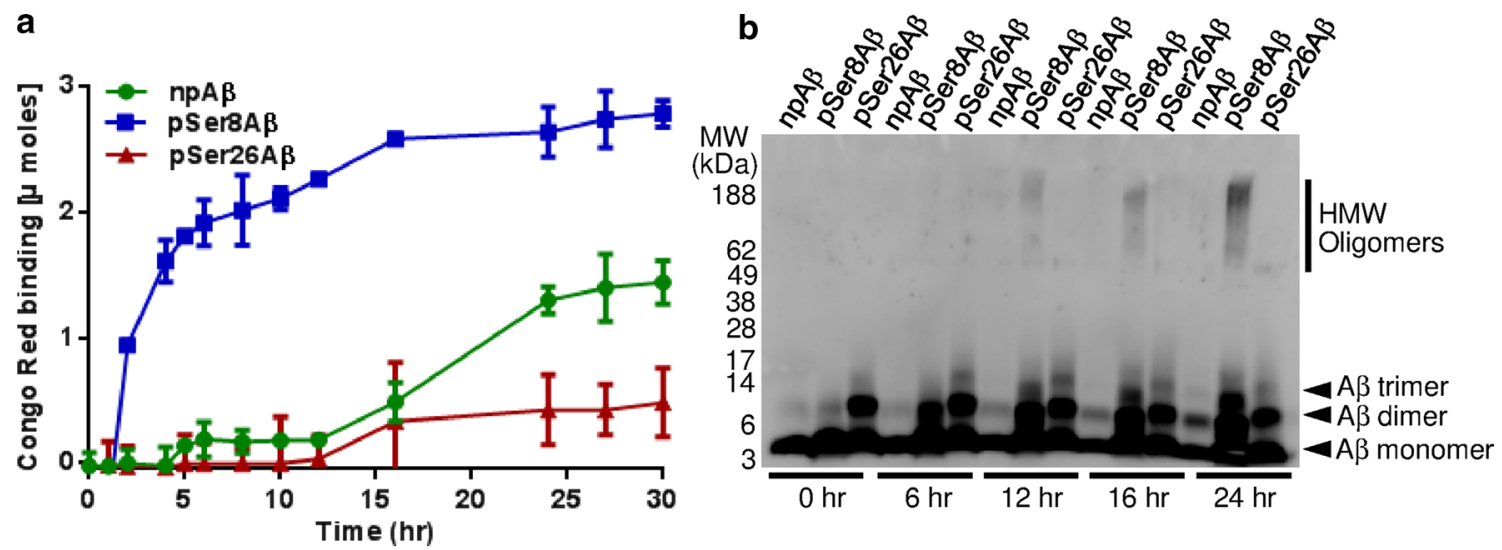

C
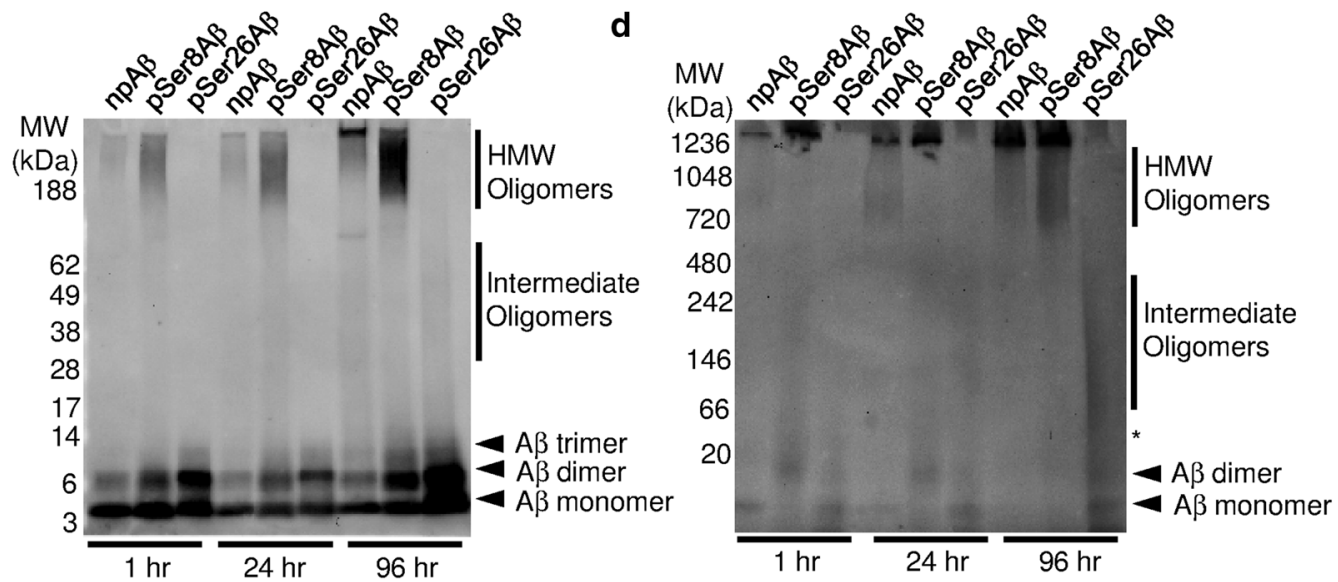

e
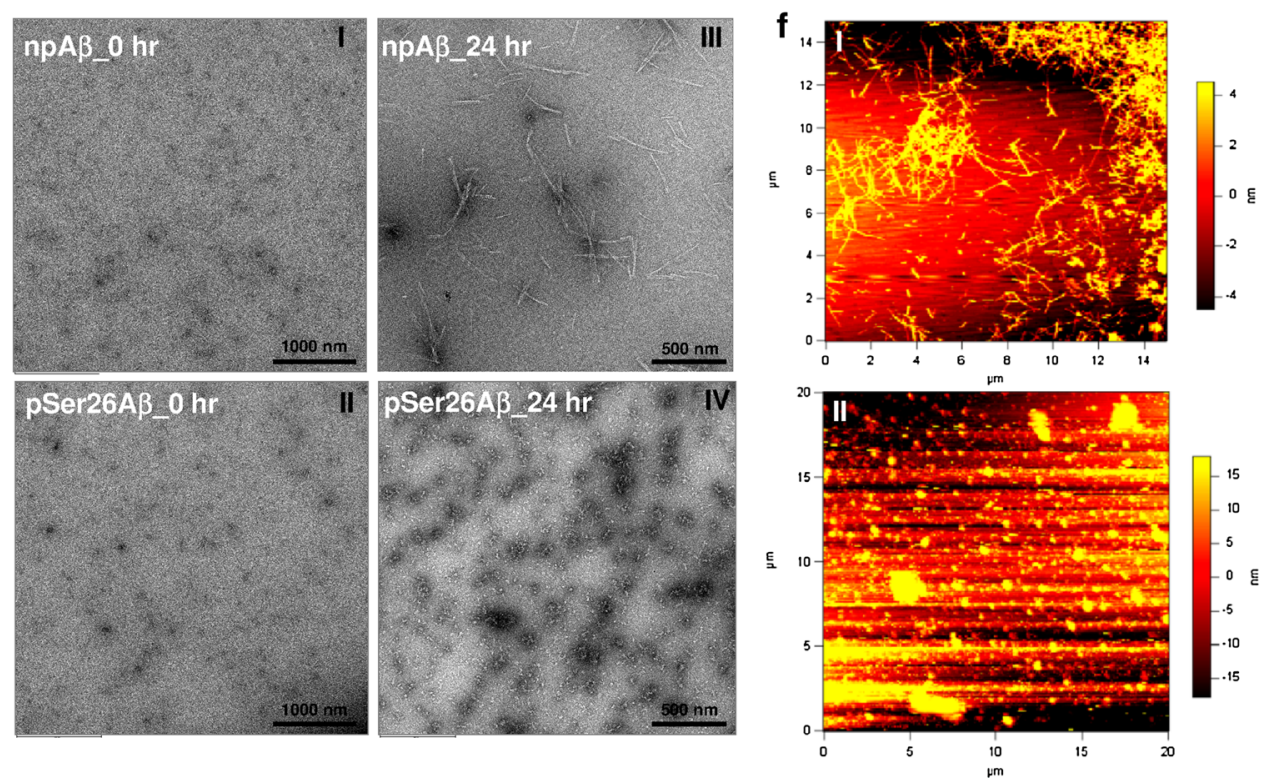

may be inert or even protective $[1,4,15,19,47]$. Thus, $A \beta$ peptide aggregation into toxic, soluble oligomers is considered as an important event in the pathogenesis of $\mathrm{AD}[31$, $32,53]$. This is also supported by findings with transgenic animal models where pathological changes are frequently observed prior to the onset of amyloid plaque accumulation [5, 16, 49]. In addition, soluble $\mathrm{A} \beta$ correlates better with dementia than insoluble fibrillar deposits [1, 11, 31, 
4Fig. 3 pSer26A $\beta$ selectively forms oligomers without fibril formation. a Congo Red (CR) binding assay showing the decreased $\mathrm{CR}$ dye binding to pSer $26 \mathrm{~A} \beta$ as compared to $\mathrm{npA} \beta$ and pSer8A $\beta$ peptides. $\mathbf{b}$ SDS-PAGE and Western immunoblot detection of $A \beta$ variants after different times of aggregation (see also supplementary Fig. 7). SDSPAGE (c) and native-PAGE (d) analysis of the aggregates collected at different incubation time demonstrates the lack of HMW pSer26A $\beta$ assemblies, even after prolonged incubation time ( $96 \mathrm{~h})$. Monoclonal 82E1 antibody was used for immunoblotting. e Transmission electron microscopy (TEM) images demonstrate granular non-aggregated structures of npA $\beta$ and $\mathrm{pSer} 26 \mathrm{~A} \beta$ peptide samples at $0 \mathrm{~h}(\mathbf{e} I, I I)$. After $24 \mathrm{~h}$ of incubation, mature fibrils are only seen with npA $\beta$ (e $I I I)$, whereas pSer $26 \mathrm{~A} \beta$ predominantly shows spherical non-fibrillar chain-like globular structures (e IV). f Atomic force microscopy (AFM) images of $n p A \beta$ and pSer26A $\beta$ after $24 \mathrm{~h}$ of aggregation further confirm the formation of fibrillar aggregates of $\operatorname{npA} \beta(\mathbf{f}, \mathbf{i})$ and non-fibrillar globular assemblies of pSer26A $\beta$ peptide (f $I I$, see also Supplementary Fig. 8)

32, 52], further suggesting that soluble oligomeric forms of $\mathrm{A} \beta$ may represent the primary toxic species in AD pathogenesis. Our results indicate that phosphorylation at Ser26 results in the specific formation of low and intermediate molecular weight, soluble oligomers. These pSer26A $\beta$ oligomers are a persistent structural entity that remain as non-fibrillar assemblies and do not produce high molecular weight $A \beta$ oligomers or fibrils even upon extended incubation time.

Monomeric $\mathrm{A} \beta$ is intrinsically disordered in aqueous solution. During conversion into fibrils, two $\beta$-strands are formed (residues Val12-Val24 and Ala30-Val40). These two $\beta$-strands form parallel $\beta$-sheets through intermolecular hydrogen bonding, whereas the intervening region comprising residues Gly25-Gly29 forms a bend-like structure that brings the two $\beta$-sheets in contact through sidechain-sidechain interactions [35, 51]. Formation of this turn/bend-like structure from Gly 25 to Gly 29 is important for fibrillization of $A \beta$ and is one of the earliest events in $A \beta$ self-association and nucleation of $\mathrm{A} \beta$ monomers as supported by several experimental and computational studies [2, 24, 35, 38, 41, 51]. Mutations such as the Flemish (A21G), Italian (E22K), Arctic (E22G), Dutch (E22Q), Osaka (E22 $\Delta$ ), and Iowa (D23N) that cause FAD and CAA are localized close to this critical region and interfere with turn formation and fibrillization $[8,10,14,18$, 24, 25]. Furthermore, computational studies have indicated an interaction of Asp23 and Ser26 that is particularly important in organizing $A \beta$ structure [2]. As Ser26 is located within the Gly25-Gly29 turn motif, phosphorylation of Ser26 in this turn region could play a crucial role in $\mathrm{A} \beta$ monomer folding, oligomerization and assembly. Introduction of a negatively charged phosphate group at this position could cause intermolecular repulsive interactions that might lead to destabilization of the fibrillar conformation. The importance of Ser26 is further supported by studies demonstrating that substitution of this residue by proline or cysteine residues alters fibrillization of $\mathrm{A} \beta[40,55]$. Furthermore, NMR spectroscopy and molecular dynamics simulations have shown that phosphorylation of Ser26 decreases the propensity of $A \beta$ to form a $\beta$-hairpin, rigidify the region around the modification site and interfere with formation of a fibril-specific salt bridge between Asp23 and Lys28 [41]. Our present data indicate that phosphorylation at Ser 26 promotes the formation of a stable and neurotoxic $A \beta$ assembly, thereby suppressing the formation of larger prefibrillar or fibrillar assemblies with lower toxic activity.

Several studies revealed that intraneuronal accumulation of $\mathrm{A} \beta$ precedes its extracellular deposition in $\mathrm{AD}$ patients and transgenic mouse brains and correlates with neurodegeneration [5, 16, 23, 29, 56, 58]. Immunohistochemical analysis of the transgenic mouse and human brains demonstrated intracellular accumulation of $\mathrm{pSer} 26 \mathrm{~A} \beta$, thereby resembling findings on accumulation of intracellular $A \beta$ oligomers without extracellular plaques in transgenic mice expressing the APPE693 $\Delta$ mutant [49]. This FAD mutation (Osaka) is located within the $A \beta$ sequence and produces an $\mathrm{A} \beta$ variant lacking glutamate-22 (E22 $\Delta)$ that exhibits enhanced oligomerization without fibrillization [50], very similar to the behaviour of pSer26A $\beta$. Notably, the intraneuronal pSer26A $\beta$ accumulations in the human AD brain are observed in GVDs. GVDs are one of the pathological hallmarks commonly found in hippocampal pyramidal neurons of patients with aging-related neurodegenerative diseases including AD [48], and defined as electron-dense granules within double membrane-bound cytoplasmic vacuoles present in neurons, having an immunohistochemical signature that suggests that they derive from the autophagic system [12]. GVDs have been shown to present more frequently in $\mathrm{AD}$ brains as compared to age-matched controls, and increases during AD pathogenesis [48]. GVDs appear within hippocampal pyramidal neurons in $\mathrm{AD}$ when phosphorylated tau begins to aggregate into early-stage neurofibrillary tangles [46], and correlate with vulnerability and neuronal loss [48]. Characterization of GVDs by immunohistochemical methods led to the identification of protein constituents such as tau, pTDP43, together with protein kinases CK $1 \varepsilon$ and CK1 $\delta$ [20]. Interestingly, in vitro 
a

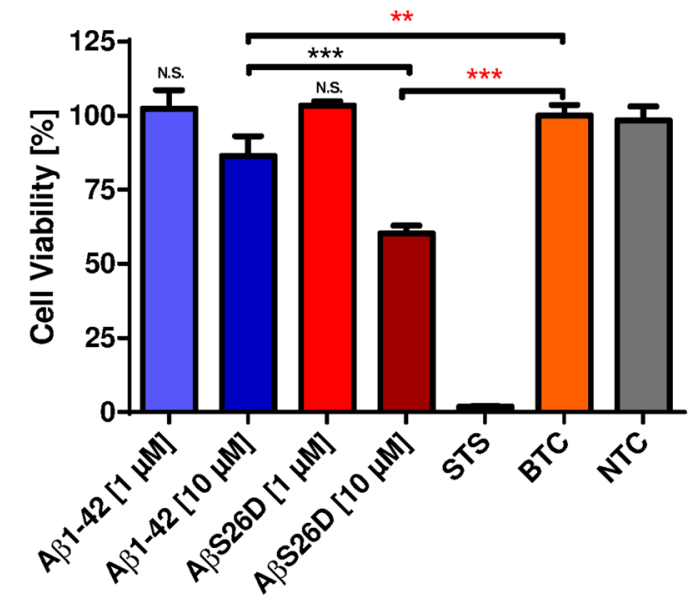

c
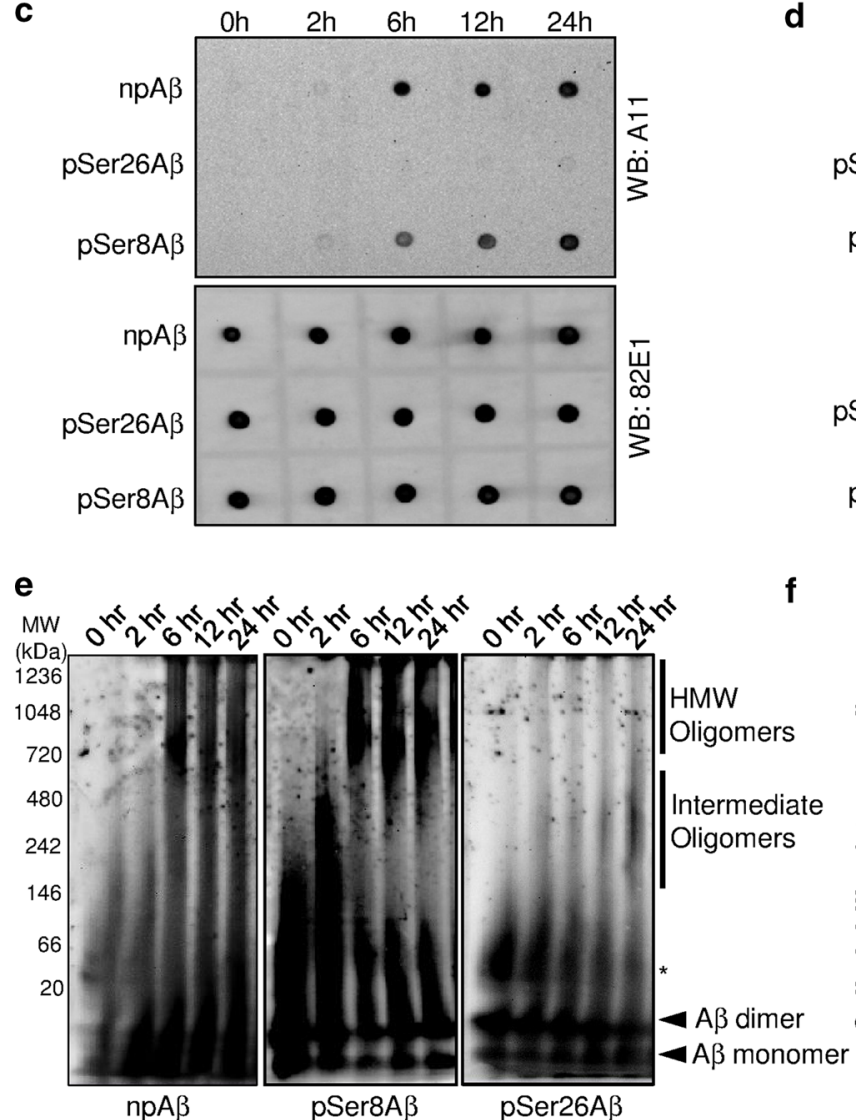

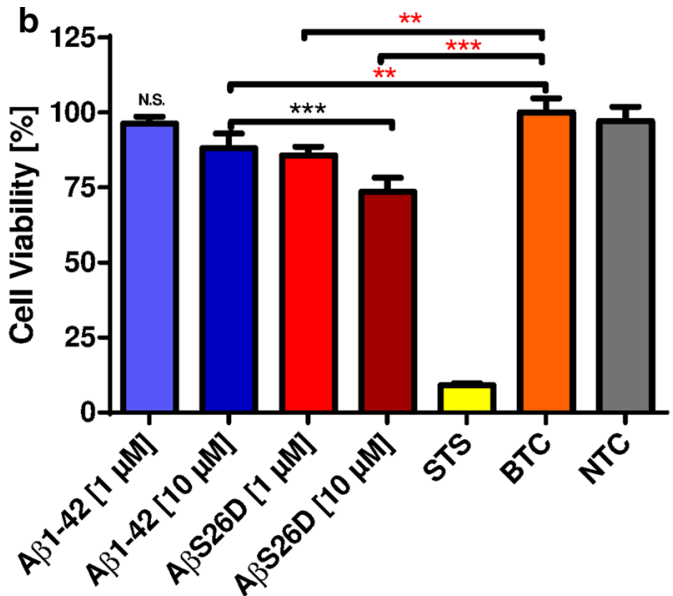

d

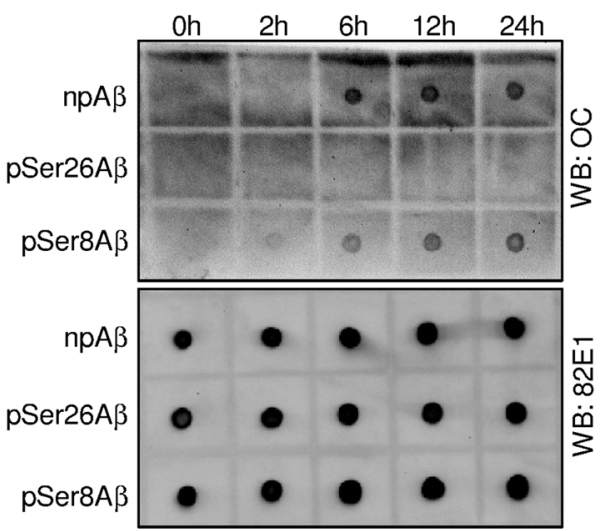

phosphorylation assays indeed show that CK1 phosphorylates Ser 26 of $A \beta$, indicating that CK1 could also phosphorylate $A \beta$ in vivo. Notably, pSer26A $\beta$-positive GVDs were also detected in pathologically preclinical $\mathrm{AD}$ (p-preAD) and non-AD controls. Thus, it will be intriguing to further analyse the role of intraneuronal pSer26A $\beta$ and progression of $\mathrm{AD}$ from pathologically preclinical $\mathrm{AD}$ or non- $\mathrm{AD}$ to AD stage. It was also suggested that neurons harbouring GVDs with phosphorylated tau accumulation reflect a 'toxic' or 'apoptotic' alterations in AD [46].

Together, the present data indicate a critical role of Ser26 phosphorylation in $\mathrm{A} \beta$ assembly and oligomerization, and its toxic properties. Thus, pSer26A $\beta$ shows similar characteristics as certain $\mathrm{A} \beta$ variants with $\mathrm{FAD}$-associated 
\Fig. 4 Increased cytotoxicity of pSer26A $\beta$. Human neuroblastoma cells (a) and embryonic stem cell-derived neurons (hESNs) (b) were incubated with $\mathrm{npA} \beta(\mathrm{A} \beta 1-42)$ and pseudophosphorylated $(A \beta S 26 D)$ peptides. Cell viability was analysed by the Presto Blue assay. Both $A \beta$ variants $(A \beta 1-42$ and $A \beta 26 D)$ did not exert toxicity at lower concentration $(1 \mu \mathrm{M})$ in neuroblastoma cells. At concentrations of $10 \mu \mathrm{M}$, the pseudophosphorylated A $\beta$ S26D variant was more toxic than the unmodified peptide. (a). In hESNs, A $\beta S 26 \mathrm{D}$ was already toxic at a $1 \mu \mathrm{M}$ concentration, where unmodified $\mathrm{A} \beta$ had no effect. At $10 \mu \mathrm{M}, \mathrm{A} \beta \mathrm{S} 26 \mathrm{D}$ also exterted pronounced toxicity as compared to unmodified $\mathrm{A} \beta$ (b). ( $p<0.01$; red stars indicate statistical significance of the indicated bar graphs versus vehicle controls; black stars indicate statistical significance between the indicated bar graph pairs; mean \pm standard error of the mean (SEM), $n=18$ replicates from 3 independent experiments). STS staurosporine treatment (positive control), BTC buffer treatment control (similar volume of PBS without A $\beta$ ), NTC non-treated control (no addition of PBS to culture media), N.S. not significant. c, d Dot blotting of npA $\beta$, pSer8A $\beta$ and $\mathrm{pSer} 26 \mathrm{~A} \beta$ variants collected at the indicated time periods of incubation $(0,2,6,12$ and $24 \mathrm{~h})$ with conformation-dependent anti-amyloid oligomer-specific A11 (c upper panel) and OC (d upper panel) antibodies. Reprobing of the membranes with generic 82E1 antibody confirms the presence of $\mathrm{A} \beta$ variants (c, $\mathbf{d}$ lower panels). e Native-PAGE of the npA $\beta$, pSer8A $\beta$ and pSer26A $\beta$ samples shows the kinetic differences in formation intermediate and HMW A $\beta$ assemblies. Mouse monoclonal 82E1 antibody was used for probing the blots. Asterisk indicates trimeric/tetrameric $\mathrm{A} \beta$ assemblies. f Aggregates of $\mathrm{npA} \beta$, pSer8A $\beta$ and pSer26A $\beta$ were added to induced pluripotent stem cell (iPSC)-derived neurons and incubated for $50 \mathrm{~h}$. The most cytotoxic species observed were the pSer26A $\beta$ aggregates after $24 \mathrm{~h}$ of aggregation $(p<0.01$; red stars signify statistical significance of the indicated bar graphs versus buffer controls; black stars signify statistical significance between the indicated bar graph pairs; mean \pm SEM)

mutations at Ala21, Glu22 and Asp23 [7, 13, 18, 23, 25, 34, $49,50]$. In contrast to these very rare mutations, phosphorylation of Ser26 can occur on wild-type $A \beta$ and was commonly detected in the brains of sporadic human $\mathrm{AD}$ cases and several AD mouse models. Thus, pSer26A $\beta$ might be critically involved in the pathogenesis of the most common sporadic late-onset forms of $\mathrm{AD}$.

Acknowledgments We thank Dr. U. Knippschild for providing anti CK1 antibodies. This work was supported by the Deutsche Forschungsgemeinschaft (WA1477/6, SFB645, KFO177), Alzheimer Forschungs Initiative (\#12854), German Federal Ministry for Education and Research (BMBF: BioPharma-NeuroAllianz Grants 1615608A and 1615608B), European Commission (FP7-HEALTH2010-266753-SCR\&Tox, COLIPA) and the Hertie Foundation.

Author information $\mathrm{OB}$ is co-founder of and has stock in LIFE \& BRAIN GmbH. Lt-NES ${ }^{\circledR}$ is a registered trademark of LIFE \& BRAIN GmbH.

Open Access This article is distributed under the terms of the Creative Commons Attribution 4.0 International License (http://creativecommons.org/licenses/by/4.0/), which permits unrestricted use, distribution, and reproduction in any medium, provided you give appropriate credit to the original author(s) and the source, provide a link to the Creative Commons license, and indicate if changes were made.

\section{References}

1. Baglioni S, Casamenti F, Bucciantini M, Luheshi LM, Taddei N, Chiti F, Dobson CM, Stefani M (2006) Prefibrillar amyloid aggregates could be generic toxins in higher organisms. J Neurosci 26:8160-8167

2. Baumketner A, Bernstein SL, Wyttenbach T, Lazo ND, Teplow DB, Bowers MT, Shea JE (2006) Structure of the 21-30 fragment of amyloid beta-protein. Protein Sci 15:1239-1247

3. Bemporad F, Chiti F (2012) Protein misfolded oligomers: experimental approaches, mechanism of formation, and structure-toxicity relationships. Chem Biol 19:315-327

4. Benilova I, Karran E, De SB (2012) The toxic Abeta oligomer and Alzheimer's disease: an emperor in need of clothes. Nat Neurosci 15:349-357

5. Billings LM, Oddo S, Green KN, McGaugh JL, LaFerla FM (2005) Intraneuronal Abeta causes the onset of early Alzheimer's disease-related cognitive deficits in transgenic mice. Neuron 45:675-688

6. Braak H, Braak E (1991) Neuropathological stageing of Alzheimer-related changes. Acta Neuropathol 82:239-259

7. Chiti F, Stefani M, Taddei N, Ramponi G, Dobson CM (2003) Rationalization of the effects of mutations on peptide and protein aggregation rates. Nature 424:805-808

8. Chong SH, Yim J, Ham S (2013) Structural heterogeneity in familial Alzheimer's disease mutants of amyloid-beta peptides. Mol BioSyst 9:997-1003

9. Citron M, Oltersdorf T, Haass C, McConlogue L, Hung AY, Seubert P, Vigo-Pelfrey C, Lieberburg I, Selkoe DJ (1992) Mutation of the beta-amyloid precursor protein in familial Alzheimer's disease increases beta-protein production. Nature 360:672-674

10. Fawzi NL, Kohlstedt KL, Okabe Y, Head-Gordon T (2008) Protofibril assemblies of the arctic, Dutch, and Flemish mutants of the Alzheimer's Abeta1-40 peptide. Biophys J 94:2007-2016

11. Ferreira ST, Lourenco MV, Oliveira MM, De Felice FG (2015) Soluble amyloid-beta oligomers as synaptotoxins leading to cognitive impairment in Alzheimer's disease. Front Cell Neurosci 9:191

12. Funk KE, Mrak RE, Kuret J (2011) Granulovacuolar degeneration (GVD) bodies of Alzheimer's disease (AD) resemble late-stage autophagic organelles. Neuropathol Appl Neurobiol 37:295-306

13. Gandy S, Simon AJ, Steele JW, Lublin AL, Lah JJ, Walker LC, Levey AI, Krafft GA, Levy E, Checler F, Glabe C, Bilker WB, Abel T, Schmeidler J, Ehrlich ME (2010) Days to criterion as an indicator of toxicity associated with human Alzheimer amyloidbeta oligomers. Ann Neurol 68:220-230

14. Gessel MM, Bernstein S, Kemper M, Teplow DB, Bowers MT (2012) Familial Alzheimer's disease mutations differentially alter amyloid beta-protein oligomerization. ACS Chem Neurosci 3:909-918

15. Glabe CG (2008) Structural classification of toxic amyloid oligomers. J Biol Chem 283:29639-29643

16. Gouras GK, Almeida CG, Takahashi RH (2005) Intraneuronal Abeta accumulation and origin of plaques in Alzheimer's disease. Neurobiol Aging 26:1235-1244

17. Gouras GK, Tampellini D, Takahashi RH, Capetillo-Zarate E (2010) Intraneuronal beta-amyloid accumulation and synapse pathology in Alzheimer's disease. Acta Neuropathol 119:523-541

18. Grant MA, Lazo ND, Lomakin A, Condron MM, Arai H, Yamin G, Rigby AC, Teplow DB (2007) Familial Alzheimer's disease mutations alter the stability of the amyloid betaprotein monomer folding nucleus. Proc Natl Acad Sci USA 104:16522-16527 
19. Haass C, Selkoe DJ (2007) Soluble protein oligomers in neurodegeneration: lessons from the Alzheimer's amyloid beta-peptide. Nat Rev Mol Cell Biol 8:101-112

20. Kannanayakal TJ, Tao H, Vandre DD, Kuret J (2006) Casein kinase-1 isoforms differentially associate with neurofibrillary and granulovacuolar degeneration lesions. Acta Neuropathol 111:413-421

21. Kayed R, Head E, Sarsoza F, Saing T, Cotman CW, Necula M, Margol L, Wu J, Breydo L, Thompson JL, Rasool S, Gurlo T, Butler P, Glabe CG (2007) Fibril specific, conformation dependent antibodies recognize a generic epitope common to amyloid fibrils and fibrillar oligomers that is absent in prefibrillar oligomers. Mol Neurodegener 2:18

22. Kayed R, Head E, Thompson JL, McIntire TM, Milton SC, Cotman CW, Glabe CG (2003) Common structure of soluble amyloid oligomers implies common mechanism of pathogenesis. Science 300:486-489

23. Knobloch M, Konietzko U, Krebs DC, Nitsch RM (2007) Intracellular Abeta and cognitive deficits precede beta-amyloid deposition in transgenic arcAbeta mice. Neurobiol Aging 28:1297-1306

24. Krone MG, Baumketner A, Bernstein SL, Wyttenbach T, Lazo ND, Teplow DB, Bowers MT, Shea JE (2008) Effects of familial Alzheimer's disease mutations on the folding nucleation of the amyloid beta-protein. J Mol Biol 381:221-228

25. Kulic L, McAfoose J, Welt T, Tackenberg C, Spani C, Wirth F, Finder V, Konietzko U, Giese M, Eckert A, Noriaki K, Shimizu T, Murakami K, Irie K, Rasool S, Glabe C, Hock C, Nitsch RM (2012) Early accumulation of intracellular fibrillar oligomers and late congophilic amyloid angiopathy in mice expressing the Osaka intra-Abeta APP mutation. Transl Psychiatry 2:e183

26. Kumar S, Rezaei-Ghaleh N, Terwel D, Thal DR, Richard M, Hoch M, Mc Donald JM, Wullner U, Glebov K, Heneka MT, Walsh DM, Zweckstetter M, Walter J (2011) Extracellular phosphorylation of the amyloid beta-peptide promotes formation of toxic aggregates during the pathogenesis of Alzheimer's disease. EMBO J 30:2255-2265

27. Kumar S, Singh S, Hinze D, Josten M, Sahl HG, Siepmann M, Walter J (2012) Phosphorylation of amyloid-beta peptide at serine 8 attenuates its clearance via insulin-degrading and angiotensin-converting enzymes. J Biol Chem 287:8641-8651

28. Kumar S, Walter J (2011) Phosphorylation of amyloid beta (Abeta) peptides - a trigger for formation of toxic aggregates in Alzheimer's disease. Aging (Albany NY) 3:803-812

29. Kumar S, Wirths O, Theil S, Gerth J, Bayer TA, Walter J (2013) Early intraneuronal accumulation and increased aggregation of phosphorylated Abeta in a mouse model of Alzheimer's disease. Acta Neuropathol 125:699-709

30. Kummer MP, Hermes M, Delekarte A, Hammerschmidt T, Kumar S, Terwel D, Walter J, Pape HC, Konig S, Roeber S, Jessen F, Klockgether T, Korte M, Heneka MT (2011) Nitration of tyrosine 10 critically enhances amyloid beta aggregation and plaque formation. Neuron 71:833-844

31. Larson ME, Lesne SE (2012) Soluble Abeta oligomer production and toxicity. J Neurochem 120(Suppl 1):125-139

32. Lesne SE, Sherman MA, Grant M, Kuskowski M, Schneider JA, Bennett DA, Ashe KH (2013) Brain amyloid-beta oligomers in ageing and Alzheimer's disease. Brain 136:1383-1398

33. Liu P, Reed MN, Kotilinek LA, Grant MK, Forster CL, Qiang W, Shapiro SL, Reichl JH, Chiang AC, Jankowsky JL, Wilmot CM, Cleary JP, Zahs KR, Ashe KH (2015) Quaternary structure defines a large class of amyloid-beta oligomers neutralized by sequestration. Cell Rep 11:1760-1771

34. Lord A, Kalimo H, Eckman C, Zhang XQ, Lannfelt L, Nilsson LN (2006) The arctic Alzheimer mutation facilitates early intraneuronal Abeta aggregation and senile plaque formation in transgenic mice. Neurobiol Aging 27:67-77

35. Luhrs T, Ritter C, Adrian M, Riek-Loher D, Bohrmann B, Dobeli H, Schubert D, Riek R (2005) 3D structure of Alzheimer's amyloid-beta(1-42) fibrils. Proc Natl Acad Sci USA 102:17342-17347

36. Milton NG (2001) Phosphorylation of amyloid-beta at the serine 26 residue by human cdc2 kinase. NeuroReport 12:3839-3844

37. Mirra SS, Heyman A, McKeel D, Sumi SM, Crain BJ, Brownlee LM, Vogel FS, Hughes JP, van BG, Berg L (1991) The Consortium to Establish a Registry for Alzheimer's Disease (CERAD). Part II. Standardization of the neuropathologic assessment of Alzheimer's disease. Neurology 41:479-486

38. Murray MM, Krone MG, Bernstein SL, Baumketner A, Condron MM, Lazo ND, Teplow DB, Wyttenbach T, Shea JE, Bowers MT (2009) Amyloid beta-protein: experiment and theory on the 21-30 fragment. J Phys Chem B 113:6041-6046

39. Nussbaum JM, Schilling S, Cynis H, Silva A, Swanson E, Wangsanut T, Tayler K, Wiltgen B, Hatami A, Ronicke R, Reymann K, Hutter-Paier B, Alexandru A, Jagla W, Graubner S, Glabe CG, Demuth HU, Bloom GS (2012) Prion-like behaviour and tau-dependent cytotoxicity of pyroglutamylated amyloidbeta. Nature 485:651-655

40. O'Nuallain B, Freir DB, Nicoll AJ, Risse E, Ferguson N, Herron CE, Collinge J, Walsh DM (2010) Amyloid beta-protein dimers rapidly form stable synaptotoxic protofibrils. J Neurosci 30:14411-14419

41. Rezaei-Ghaleh N, Amininasab M, Giller K, Kumar S, Stundl A, Schneider A, Becker S, Walter J, Zweckstetter M (2014) Turn plasticity distinguishes different modes of amyloid-beta aggregation. J Am Chem Soc 136:4913-4919

42. Rijal UA, Kosterin I, Kumar S, von Arnim CA, Yamaguchi H, Fandrich M, Walter J, Thal DR (2014) Biochemical stages of amyloid-beta peptide aggregation and accumulation in the human brain and their association with symptomatic and pathologically preclinical Alzheimer's disease. Brain 137:887-903

43. Schilling S, Zeitschel U, Hoffmann T, Heiser U, Francke M, Kehlen A, Holzer M, Hutter-Paier B, Prokesch M, Windisch M, Jagla W, Schlenzig D, Lindner C, Rudolph T, Reuter G, Cynis H, Montag D, Demuth HU, Rossner S (2008) Glutaminyl cyclase inhibition attenuates pyroglutamate Abeta and Alzheimer's disease-like pathology. Nat Med 14:1106-1111

44. Selkoe DJ (2008) Soluble oligomers of the amyloid beta-protein impair synaptic plasticity and behavior. Behav Brain Res 192:106-113

45. St George-Hyslop PH, Petit A (2005) Molecular biology and genetics of Alzheimer's disease. C R Biol 328:119-130

46. Stadelmann C, Deckwerth TL, Srinivasan A, Bancher C, Bruck W, Jellinger K, Lassmann H (1999) Activation of caspase-3 in single neurons and autophagic granules of granulovacuolar degeneration in Alzheimer's disease. Evidence for apoptotic cell death. Am J Pathol 155:1459-1466

47. Stefani M (2012) Structural features and cytotoxicity of amyloid oligomers: implications in Alzheimer's disease and other diseases with amyloid deposits. Prog Neurobiol 99:226-245

48. Thal DR, Del TK, Ludolph AC, Hoozemans JJ, Rozemuller AJ, Braak H, Knippschild U (2011) Stages of granulovacuolar degeneration: their relation to Alzheimer's disease and chronic stress response. Acta Neuropathol 122:577-589

49. Tomiyama T, Matsuyama S, Iso H, Umeda T, Takuma H, Ohnishi K, Ishibashi K, Teraoka R, Sakama N, Yamashita T, Nishitsuji K, Ito K, Shimada H, Lambert MP, Klein WL, Mori H (2010) A mouse model of amyloid beta oligomers: their contribution to synaptic alteration, abnormal tau phosphorylation, glial activation, and neuronal loss in vivo. J Neurosci 30:4845-4856 
50. Tomiyama $\mathrm{T}$, Nagata $\mathrm{T}$, Shimada $\mathrm{H}$, Teraoka R, Fukushima A, Kanemitsu H, Takuma H, Kuwano R, Imagawa M, Ataka S, Wada Y, Yoshioka E, Nishizaki T, Watanabe Y, Mori H (2008) A new amyloid beta variant favoring oligomerization in Alzheimer's-type dementia. Ann Neurol 63:377-387

51. Tycko R (2015) Amyloid polymorphism: structural basis and neurobiological relevance. Neuron 86:632-645

52. Viola KL, Klein WL (2015) Amyloid beta oligomers in Alzheimer's disease pathogenesis, treatment, and diagnosis. Acta Neuropathol 129:183-206

53. Walsh DM, Selkoe DJ (2007) A beta oligomers—a decade of discovery. J Neurochem 101:1172-1184

54. Walter J, Kaether C, Steiner H, Haass C (2001) The cell biology of Alzheimer's disease: uncovering the secrets of secretases. Curr Opin Neurobiol 11:585-590

55. Williams AD, Shivaprasad S, Wetzel R (2006) Alanine scanning mutagenesis of Abeta(1-40) amyloid fibril stability. J Mol Biol $357: 1283-1294$
56. Wirths O, Bayer TA (2012) Intraneuronal Abeta accumulation and neurodegeneration: lessons from transgenic models. Life Sci 91:1148-1152

57. Wirths O, Erck C, Martens H, Harmeier A, Geumann C, Jawhar S, Kumar S, Multhaup G, Walter J, Ingelsson M, DegermanGunnarsson M, Kalimo H, Huitinga I, Lannfelt L, Bayer TA (2010) Identification of low molecular weight pyroglutamate A $\{$ beta $\}$ oligomers in Alzheimer disease: a novel tool for therapy and diagnosis. J Biol Chem 285:41517-41524

58. Wirths O, Multhaup G, Czech C, Blanchard V, Moussaoui S, Tremp G, Pradier L, Beyreuther K, Bayer TA (2001) Intraneuronal Abeta accumulation precedes plaque formation in betaamyloid precursor protein and presenilin-1 double-transgenic mice. Neurosci Lett 306:116-120 